\title{
Beckett's Intermedial Ecosystems. Closed Space Environments across the Stage, Prose and Media Works
}

Anna McMullan (2021).

London: Cambridge University Press.

0

Vanesa Cotroneo

Universidad Friedrich Alexander Erlangern, Nürnberg

El texto de Anna McMullan (2021), Beckett's Intermedial Ecosystems. Closed Space Environments across the Stage, Prose and Media Works, pertenece a la serie Elements in Beckett Studies, dirigida por Dirk Van Hulle y Mark Nixon, editada por Cambridge University Press ${ }^{1}$. El objetivo de dicha serie es presentar los trabajos de investigadores distinguidos y recientes, dando espacio a los debates más relevantes en torno a los estudios sobre Samuel Beckett como así también a aquellos aspectos de su obra que se encuentren desplazados.

Los elementos de la serie son textos escritos en inglés, no demasiado extensos pero que focalizan en un aspecto de la obra del autor irlandés. En este caso puntual, Anna McMullan, Profesora de Teatro y Directora de Investigación de Cine, Teatro y Televisión en la Universidad de Reading, Inglaterra, se concentra en la obra de Beckett y su relación con el espacio, entendiendo sus pliegues entre los diversos géneros teatrales, narrativos y audiovisuales, como ecosistemas intermediales.

Haciendo uso de conceptos como el Antropoceno, la ecocrítica, pero también el theatrum mundi y las tecnologías de la observación, la autora desarrolla una hipótesis según la cual los elementos de la biosfera beckettiana no dependen de la acción humana sino que, por el contrario, son éstos cuerpos subjetivos expulsados a escena por la acción del autor y/o por los equipos técnicos. En una suerte de microcosmos sobre el cual el medio ambiente externo ejerce su control, los personajes de Beckett se encuentran reducidos a una especie exhausta (McMullan: 2021,

1. La serie Elements in Beckett Studies fue presentada en el número 17 de Beckettiana, en la reseña de la Dra. Castagnino "Experimental Beckett: Contemporary Performance Practices, de Nicholas E. Johnson y Jonathan Heron”. p.7), que sobrevive, de algún modo, aplicando sus propios mecanismos de generación y control.

McMullan relaciona el concepto del microcosmos con la idea del theatrum mundi y con la tradición ligada a él, mencionando particularmente a Shakespeare y el Renacimiento, pero también a Bertolt Brecht, Jean Genet, Peter Weiss y el propio Samuel Beckett. A partir del segundo capítulo, "The Theatrum Mundi as Ecosystem: Beckett's Mimes and Dramatic Fragments", hasta el capítulo cuarto "Televisual Systems and Romantic Ghosts of the Anthropocene", pasando por el tercero "Exhausted Biospheres and Techniques of Observation: the Closed Space Prose Texts", la idea del theatrum mundi como hilo conductor de la exposición, ya postulada por Ruby Cohn en su ensayo de 1967, y retomada por James Knowlson luego de 1975, es desarrollada y ampliada. Al respecto, McMuIlan nos recuerda que Ruby Cohn se había focalizado en la conciencia de los personajes beckettianos acerca de estar siendo observados, lo cual incluye la posibilidad de la audiencia teatral como testigo, algo que Cohn reconoce particularmente en Endgame. Asimismo, señala McMullan que el biógrafo de Beckett, Knowlson, luego de la puesta de Warten auf Godot para el Schiller-Theater Berlin en 1975, había notado la articulación entre una serie de contrastes elementales o cosmológicos (McMullan: 2021, p.12), tales como tierra y cielo, lo mineral y lo vegetal, o lo horizontal y lo vertical, en cuyo caso, Vladimir y Estragón no se encuentran en un espacio cerrado pero sí en un escenario-cosmos con sus propias y mecánicas reglas, también inquiriendo, por ejemplo, al Muchacho, si han sido vistos. Luego de estas reflexiones, la crítica menciona a Jonathan Crary y su texto Techniques of the Observer: On Vision and Modernity in the Nineteenth Century (1990) para identificar en Endgame el cambio que Crary propone en la conciencia europea, ya que la visión autónoma con clara separación 
entre el observador y el objeto observado supone una contradicción con los modos más fisiológicos y subjetivos de mirar, por ejemplo, a través de tecnologías como el catalejo, que aumenta pero fractura la visión. Al respecto, señala la autora que Endgame articula la nostalgia por la captura visual del mundo, asociada a la perspectiva de theatrum mundi, y la imposibilidad de toda estabilidad de la visión, incluyendo la del espectador (McMullan: 2021, p.13). En este punto, McMullan realiza una certera afirmación al reconocer que, en obras como Play y Catastrophe, tanto en la situación de las urnas y su vínculo con interrogatorios y juicios, como en la de la tortura, las tecnologías del teatro le otorgan al público el rol de testigo en este juego del theatrum mundi. Al respecto de este último, McMullan comenta que el mismo ha ido mutando en la obra beckettiana, y que reemerge en los textos en prosa de los años ' 60 y en las piezas para televisión de las subsecuentes décadas.

En cuanto a las obras en prosa y su vínculo con el espacio cerrado, indica McMullan que, en estos ámbitos por ella denominados 'ecosistemas', existe una particular yuxtaposición entre el mundo exterior, ya sea urbano o rural, y el espacio interior de la psiquis del protagonista (McMullan: 2021, p.24), como lo demuestran los recorridos descendientes espaciotemporales en How It Is, o la ubicación de All Strange Away, la cual, inicialmente, es estática, pero cuyas figuras se organizan en continuas permutaciones de diferentes posiciones, algo posible dado el aspecto entrópico de dichos ecosistemas. También en Imagination Dead Imagine dos cuerpos se encuentran sujetos a fuerzas climáticas y espaciales, sin referencias claras a alguna marca de género identitaria.

Finalmente, en el cuarto y último capítulo, McMullan se focaliza en los sistemas televisivos de Beckett y en la idea de la experimentación con las tecnologías a lo largo de la década del sesenta, que le permitieron al autor indagar en un universo aún más cerrado y en los modos de recepción del medio a través del cual dichos sistemas fueron creados. Como afirma la auto$\mathrm{ra}$, incluso ante el intento de escapar por parte de $\mathrm{O}$ en Film, como ante el intento de Joe por no escuchar en Eh Joe, los espacios cerrados fallan en ser inexpugnables (McMullan: 2021, p.44). Sin dudas, el espacio físico de un estudio televisivo enfatiza la geometría visual y el encierro, algo que sucede también en Ghost Trio, ...but the clouds... y Nacht und Träume, obras vinculadas a la idea personajes convocando fantasmas de un Antropoceno romántico (McMullan: 2021, p.46) y que recurren al elemento alemán. En efecto, tal como señala Nixon, sin demasiado texto, el foco se encuentra en la manipulación de la tecnología en relación a un sentido de pérdida y ausencia, que deja al sujeto aislado (citado por McMullan: 2021, p.47). Más aún, ante la ausencia de palabras, del encuentro, el único consuelo se produce a través de la música, particularmente, de Beethoven. Ausencias, fantasmas y ecos que serán retomados en Quad y What Where, entendidos como los Endgames del Antropoceno, tal como los llama la autora (McMullan: 2021, p. 53). En estas obras, el autor incorpora música de Schubert, Die Winterreise, que presenta la repetición de un tiempo cíclico sin progreso, es decir, donde aparece, nuevamente, la idea de circularidad como en Endgame.

Para concluir, McMullan recurre a la perspectiva ecocrítica, que reconoce otras maneras de ser en el mundo, enfatizando el escepticismo de Beckett acerca de posibilidad de la acción humana sobre otros seres, el medio ambiente o el yo, representando dicha agencia más que en el sujeto, en sus extensiones tecnológicas o sus medioambientes.

El texto de McMullan nos presenta un novedoso análisis sobre la función, agencia y rol de los espacios beckettianos bajo la adecuada categoría de ecosistemas intermediales. 